\title{
Siklon Ayırıcılarda Kritik Çap Tahmini için Kullanılan Matematik Modellerin Giriş Hızı Değişiminde Davranışlarının İncelenmesi
}

\author{
*1 Ali Galip Mumcu ve ${ }^{2}$ Atakan Avc1 \\ *1Bilecik Şeyh Edebali Üniversitesi Osmaneli MYO Makine Programı, Türkiye \\ ${ }^{2}$ Bursa Uludağ Üniversitesi Mühendislik Fakültesi Makine Mühendisliği Bölümü, Türkiye
}

\section{Özet :}

Bir siklon ayırıcıda düşük basınç düşüşü ve yüksek partikül tutma verimi gerçekleşmesi istenir. $\mathrm{Bu}$ bakımdan siklon ayırıcıların performanslarının tayininde kritik çap önemli bir parametredir. Performansa etkiyen önemli parametrelerden biri de hızdır. Bu çalışmada giriş hızı değişiminin etkisini tahmin için kullanılan ve literatürde mevcut matematik modellerden 10 tanesi yine literatürde mevcut hız değişimini inceleyen yaklaşık 120 farklı deneysel veri esas alınarak incelenmiştir. Hız değişimi etkisinde matematiksel model hesaplamaları ile elde edilen kritik çap değerleri ve değişim oranları ile deneysel çalışmalarda verilen kritik çap değerleri ve değişim oranları kıyaslanmıştır. Sonuçta kritik çapın hızın karekökünden daha hızlı değişim gösterdiği görülmüştür. Buna göre kritik çap tahmininde hızın etkisi açısından hıza bağlı ilave terimler içeren veya sürtünme kayıplarındaki değişimi dikkate alan modellerin daha duyarlı olduğu sonucuna varılmıştır.

Anahtar Kelimeler: Siklon ayırıcılar, kritik çap, siklon ayırma verimliliği, matematik model

\begin{abstract}
:
Low pressure drop and high particle collection efficiency are desired in a cyclone separator. In this respect, the critical diameter is an important parameter in determining the performance of cyclone separators. One of the important parameters affecting performance is velocity. In this study, 10 of the existing mathematical models in the literature, which are used to predict the effect of the input velocity change, were examined on the basis of approximately 120 different experimental data examining the velocity change available in the literature. The critical diameter values and change rates obtained by mathematical model calculations under the effect of velocity change were compared with the critical diameter values and change rates given in experimental studies. As a result, it was seen that the critical diameter changes faster than the square root of the velocity. Accordingly, it was concluded that models containing additional terms related to speed or considering the change in friction losses are more sensitive in terms of the effect of velocity in estimating the critical diameter.
\end{abstract}

Key Words: Cyclone separators, critical diameter, cyclone collection efficiency, mathematical models

\section{Giriş}

Siklon ayırıcılar, içerisinde meydana gelen girdabın etkisi ile oluşan merkezkaç kuvvet ile iki fazlı akışlarda yoğun olan fazın siklon duvarına doğru radyal olarak hareket ederek daha az yoğun olan fazdan ayrılması işlemini gerçekleştirmektedir. Siklon ayırıcılar düşük ilk yatırım ve bakım maliyetleri, hareketli parçalarının az olması ve farklı çalışma koşullarında (farklı basınç ve sıcaklık koşulları gibi) verimli çalışabilmesi sebebiyle enerji santrallerinde, elektrik süpürgelerinde, toz numune alma cihazlarında, doğalgaz transferinde, kurutucularda, partikül

*Sorumlu Yazar: Ali Galip Mumcu Adres: Osmaneli Meslek Yüksekokulu, Bilecik Şeyh Edebali Üniversitesi, Bilecik Türkiye. E-posta adresi: aligalip.mumcu@ bilecik.edu.tr, Phone: +902282141962 
yoğun olan ortamlarda ve bunun gibi birçok endüstriyel uygulama da sıklıkla kullanım alanı bulmaktadır. Siklon ayırıcıların performansları değerlendirilirken iki parametre üzerinde durulmaktadır. Bir siklon ayırıcının performansının yüksek olması yüksek ayırma verimliliği ve düşük basınç düşüşü ile belirlenmektedir. Bu parametrelerden ayırma verimliliği ile ilgili diğer önemli kavram kritik çaptır. Siklon ayırıcılarda kritik çap siklon $\% 50$ verim ile çalışırken tuttuğu partikül çapını ifade eder.

Siklon ayırıcıların performanslarının tespit edilebilmesi için literatürde yapılan birçok çalışma mevcuttur. $\mathrm{Bu}$ çalışmalar deneysel, nümerik ve matematiksel model çalışmaları olarak sınıflandırılabilir. Pratik kullanım açısından matematik modeller ön plana çıkmaktadır. Bu anlamda oluşturulan matematiksel modellerin farklı çalışma koşullarında ve farklı geometrilere sahip siklonlarda performans tahmininde ne kadar başarılı olduğu önemli bir soru işaretidir. Bu çalışma da literatürde yoğun olarak kullanılan 10 matematiksel model seçilmiştir. Siklon ayırıcılarda önemli bir parametre olan giriş hızı değişiminin incelenebilmesi için literatürde mevcut olan deneysel veriler seçilen modeller ile çözülmüştür. Burada ki amaç giriş hızı değişiminin modeller ile tahmini yapılırken oluşan hata paylarının tespiti ve farklı matematiksel modellerde elde edilen sonuçların incelenmesidir. Bu çalışma kapsamında klasik siklon ayırıcı olarak tanımlayabileceğimiz teğetsel girişli ters akışlı siklonlar incelenmiştir. Literatürde bu tipte olan siklon ayırıcılar ile yapılan deney sonuçları çalışmaya dahil edilmiştir. Giriş hızının değişiminin etkisini ve matematik modellerde kritik çap tahmini performansını inceleyebilmek için literatürde birçok deneysel çalışma mevcuttur. Bu anlamda Xiang, Park, \& Lee, (2001) koni taban açıklığı (B) farklı olan teğetsel girişli üç siklon ayırıcıyı 30, 40, 50 ve 60 1/dk giriş hızları için deneysel çalışma gerçekleştirmişlerdir [1]. Yaptıkları çalışmalarında elde ettikleri deney sonuçlarına göre aynı siklon ayırıcı için giriş hızının artması ile kritik çap değerinin düştüğü görülmektedir. Ayrıca giriş hızı sabit olarak düşünülürse siklon taban açıklık değerinin küçülmesi ile birlikte kritik çap değerinin azaldığını söyleyebiliriz. Giriş hızı değişimini inceleyebileceğimiz bir başka çalışma Ji, Xiong, Wu, Chen, \& Wu, (2009) çalışmalarıdır [2]. Bu çalışmada da yine teğetsel girişli bir siklonda konsantrasyonun sabit olduğu giriş hızının 6 ila $30 \mathrm{~m} / \mathrm{s}$ arasında değiştirildiği 10 farklı giriş hızı için deneysel kritik çap değerleri verilmiştir. Bununla birlikte deneysel sonuçlar bazı matematiksel modeller ile yapılan hesaplama sonuçları ile kıyaslanmıştır. Kim \& Lee, (1990) siklon çapı 2,19-3,11 ve 4,11 cm üç farklı siklon ayırıcı için deneysel çalışmalar gerçekleştirmişlerdir [3]. Farklı geri dönüş borusu çapı kullanılarak yapılan deneylerde 8,8-12,4-18,4 1/dk olmak üzere üç farklı giriş hızı kullanılmıştır. Beeckmans \& Kim, (1977) siklon çap1 76 ve $152 \mathrm{~mm}$ olan iki siklon ayırıcı için 6,1 ile $15,5 \mathrm{~m} / \mathrm{s}$ aralığında farklı giriş hızlarında deneysel çalışma gerçekleştirmişlerdir. Siklon performansı belirlenmesinde siklon Reynolds sayısını içeren terimlerin dahil edilmesi gerektiğini vurgulamışlardır [4]. Dirgo ve Leith (1985), 305mm çapa sahip bir Stairmand siklonu ile 5, 10, 15, 20 ve 25m/s giriş hızları için deneyler yapmışlardır. Toplama verimi ve basınç düşüşü, ortam sıcaklığı ve basıncında farklı giriş hızları için ölçülmüştür. Elde edilen deneysel fraksiyonel eğriler, çeşitli siklon verim modelleri ile kıyaslanmış ve Barth ve Leith-Licht teorilerinin en yakın sonuçlar verdiği belirtilmiştir [5]. Huang vd., (2017), siklon girişine yerleştirdikleri laminarizerin siklon basınç düşüşü, kısmi ayırma verimliliği, teğetsel hız dağılımı ve kritik çap üzerindeki etkisini incelemek için deneysel ve nümerik bir çalışma gerçekleştirmişlerdir. Bu çalışmayı $72 \mathrm{~mm}$ çapında bir siklon için 11, 15, 18 ve $21 \mathrm{~m} / \mathrm{s}$ giriş hıları için gerçekleştirmiş ve kritik çap değerlerini vermişlerdir. Laminarizer kullanılan siklonda basınç düşüşünün bir miktar arttarken kritik çapın daha düşük değerler olduğunu vurgulamışlardır [6]. Iozia \& Leith, (1990), 250 mm çapı olan bir 
siklonda farklı giriş hızlarında deneysel çalışmalar yapmışlardır [7]. G. N. Kim, Choi, \& Jung, (2007) 76mm çapa sahip siklon ayırıcı için farklı giriş hızlarında yaptıkları deneysel çalışmalarında çalıştıkları siklonlar için en iyi verimi $15 \mathrm{~m} / \mathrm{s}$ giriş hızı için gerçekleştiğini belirtmişlerdir [8]. Moore \& McFarland, (1990) dört farklı çapa sahip siklon ayırıcı için, Zhu \& Lee, (1999) ise 30,5mm çapa sahip farklı geometrilerdeki siklon ayırıcıları için farklı giriş hızlarında deneysel çalışmalar gerçekleştirmişlerdir $[9,10]$. Literatür mevcut olan bu çalışmalar teğetsel girişli ters akışlı siklonlar üzerine yapılan çalışmalardan elde edilmiştir.

$\mathrm{Bu}$ çalışmanın temel amacı literatürde kritik çap tayini için sıklıkla kullanılan 10 matematiksel modelin daha önce yapılmış olan literatürde mevcut olan deneysel veriler üzerinde çözdürülerek elde edilen hesaplanmış kritik çap değerleri ile deneysel kritik çap değerlerinin birbiri ile ne kadar uyumlu olduğunu ortaya koymaktır. Burada özellikle giriş hızı parametresi dikkate alınmıştır. Dolayısıyla farklı matematiksel modellerde giriş hızını etkileyen parametrelerin birbirinden farklı olması aynı çalışma koşullarında aynı siklon ayırıcılarda farklı sonuçların çıkmasına sebep olmaktadır.

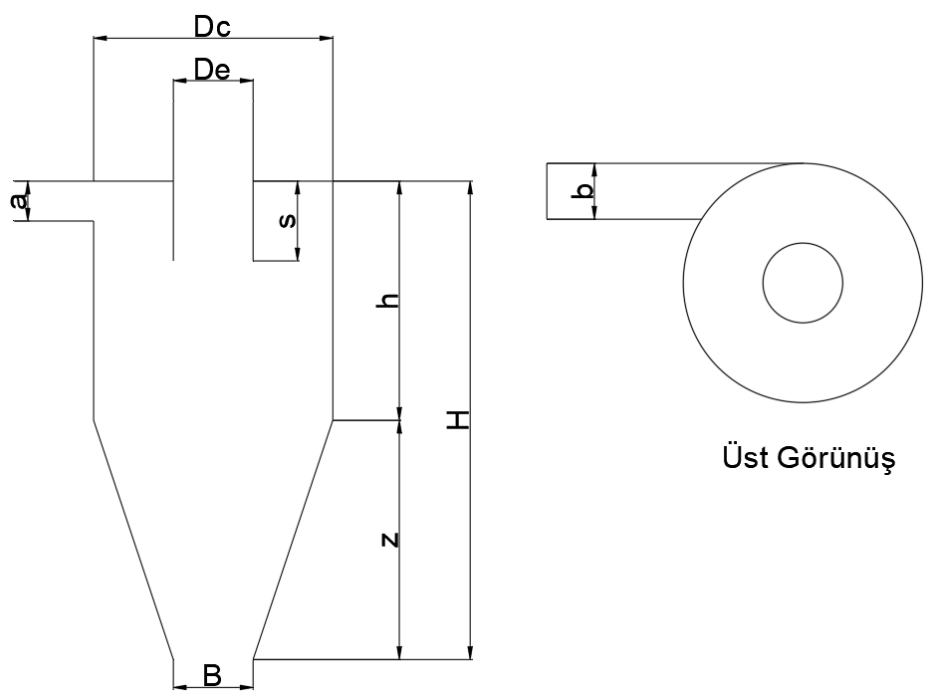

Şekil 1. Teğetsel girişli ters akışlı siklon ölçüleri

\section{Matematiksel Modeller ve Veriler}

Literatürde siklon ayırıcıların performansını (toplama verimi ve basınç düşüşü) incelemek için teorik ve yarı deneysel modeller, istatistiksel modeller, hesaplamalı akışkanlar dinamiği modelleri ve deneysel çalışmalar olmak üzere dört temel yöntemin kullanıldığı görülmektedir. Bu çalışma da siklon ayırıcılarda kritik çap tahmini için kullanılan farklı matematik modellerin giriş hızı değişimi olan siklonlarda nasıl davrandığı üzerine çalışılmıştır. Bu kapsamda literatürde mevcut olan 10 çalışmadan alınan 126 deneysel veri 10 farklı matematik model ile çözülmüştür. Çalışmada esas alınan pratikte çok kullanılan teğetsel girişli ters akışlı siklonlar için karakteristik boyutlar Şekil 1'de verilmiştir. Buna ilave olarak yüzey pürüzlülüğü, geri dönüş borusu et 
kalınlığı ve diğer akışkan ile ilgili özellikler model çalışmalarında performans tahmini için kullanılan parametrelerdir. Bu parametrelerin bazıları bazı modellerde hesaplamaya dahil iken bazı modellerde ise dahil değildir.

Siklon ayırma verimliliğini tahmin etmek için kullanılan matematik modeller genellikle "dengeyörünge" ve "uçuş süresi" olarak adlandırılan iki ilkeye dayanmakla birlikte bu iki prensibin birlikte kullanıldığı hibrit modellerde kullanılmaktadır. Denge yörünge model yaklaşımında CS olarak adlandırılan geri dönüş borusu çapının siklon tabanına devam etmesi ile oluşan hayali silindirik yüzey dikkate alınır. Bu yaklaşım CS yüzeyi üzerinde dönen bir parçacığın kuvvet dengesine dayanır. CS yüzeyi üzerindeki parçacıklara parçacıkların ağırlığı ile ilişkili olan merkezkaç kuvveti etki ederken iç kısma doğru ise sürüklenme kuvveti etki eder. Dolayısıyla büyük parçacıklar CS yüzeyinden siklon duvarına doğru hareket eder, küçük parçacıklar ise iç kısma doğru hareket ederek iç kısımda siklon tepesine doğru hareket eden iç girdaba dahil olurlar ve geri dönüş borusundan atılırlar. CS yüzeyinde parçacıklar üzerinde oluşan bu iki kuvvetin dengede olduğu parçacıklar kritik çapı belirler. Yani iki kuvvetin dengede olduğu parçacık boyutu kritik çapı ifade eder [11]. Denge yörünge modellerine örnek olarak Barth, Iozia ve Leith, Muschelknautz modelleri verilebilir.

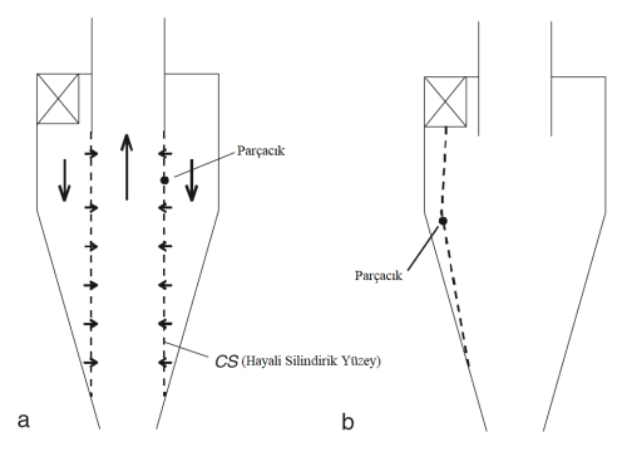

Şekil 2. a. Denge-yörünge modeli yaklaşımı b. Uçuş zamanı modeli yaklaşımı [11]

Şekil 2.b. de şematik olarak görülen uçuş zamanı model yaklaşımında siklon girişinde radyal bir pozisyonda bulunan parçacığın siklon duvarına ulaşması için gereken süre ile parçacığın siklon tabanına ulaşacağı süre dikkate alınmaktadır. Bu yaklaşımda bir parçacığın tutulabilmesi için siklon duvarına ulaşması gerekir, yani siklon duvarına ulaşması için gereken zamana ihtiyacı vardır. Eğer bir parçacık siklon duvarına ulaşamadan siklon tabanına ulaşıyorsa, bu durumda parçacık tutulmadan dışarı atılacaktır [12]. Uçuş zamanı yaklaşımında kritik çap, siklon tabanına ulaşmadan önce giriş genişliği mesafesinin yarısını geçebilen en küçük parçacık çapı olarak tanımlanır [11]. Siklon ayırıcıların verimlerinin tespitinde kullanılan matematik model yaklaşımlarından bir diğeri ise yukarıda bahsedilen iki model yaklaşımının birlikte kullanıldığı hibrit modellerdir. $\mathrm{Bu}$ modellerde denge yörünge prensibi ve uçuş zamanı prensibi birlikte kullanılir.

En yaygın kullanılan modellerden biri olan Lapple modeli siklona giren parçacıkların giriş boşluğunda eşit olarak dağıldığını varsayar. Uçuş zamanı prensibini esas alan modele göre 
parçacıkların siklonda geçen süreleri boyunca giriş yarı genişliği mesafesini geçebilen parçacık boyutu kritik çap olarak tanımlanır [16]. Merkezkaç kuvveti ile sürükleme kuvveti dengesini dikkate alan Barth modelinde herhangi bir partikül boyutu için toplama verimliliği, parçacığın çökelme hızının terminal çökelme hızına oranı olarak ifade edilir. Barth verim eşitliğinde verim ifadesi \%50 olarak alınarak kritik çap hesaplanabilir [13]. Iozia ve Leith modeli fraksiyonel verimlilik için ampirik bir ifade sunmuşlardır. Bu model Lapple ve Barth modellerinin temellerine dayanır. Leith ve Licht modelinde ise siklon içerisinde konsantrasyonun radyal yönde eşit dağıldığını varsayarak bir model geliştirmişlerdir [7,15]. Clift ve ark. önerdikleri modelde Leith ve Licht teorisinin varsayımlarına dayanarak fraksiyonel verimlilik denklemini yeniden oluşturmuşlardır [24]. Barth modelinin geliştirilmiş şekli olan Muschelknautz modeli diğer modellere ek olarak hesaplamaya bazı ek parametreleri dahil etmişlerdir. Modelde siklon ayırıcı malzemesinin yüzey pürüzlülüğü, toplanan katılardan dolayı oluşan duvar pürüzlülüğü etkileri dikkate alınmıştır. Bunun yanında partikül yükü ve partikül boyutu dağılımındaki değişiklik etkileri de model hesaplarına dahil edilmiştir [17,18,19]. Siklon duvarında parçacık sıçraması ve türbülanslı difüzyonu içeren Li ve Wang modeli, siklondaki parçacık dağılımı için iki boyutlu analitik bir ifade sunmuşlardır [22]. Avcı ve Karagöz modeli, akışkan ve partikül karışımının homojen olduğunu varsayarak akış, parçacık, geometrik parametreler ve sürtünme faktörü gibi birçok parametreyi dikkate alarak siklon performansının tahmini için eşitlikler sunmuşlardır [20]. Burada bahsedilen modeller dişında da literatürde birçok model mevcuttur. Bu çalışmada literatürde sıklıkla kullanılan ve bu çalışmada dikkate alınan 10 matematik model Tablo 1'de verilmiştir.

Tablo 1. Hesaplamalarda kullanılan matematik model denklemleri

\begin{tabular}{|c|c|c|}
\hline Matematiksel Modeller & Verim ve Kritik Çap Hesabı & Bazı Ek Denklemler \\
\hline The Barth Model [13] & $D_{50}=\left(\frac{9 \cdot \mu \cdot Q}{\pi \cdot h^{m} \cdot \rho_{p} \cdot V_{t \max }^{2}}\right)^{0,5}, \quad \eta_{i}=\frac{1}{\left[1+\left(\frac{V_{t s}}{V_{t s}^{m}}\right)^{-3,2}\right]}$ & $\begin{array}{c}\frac{V_{t s}}{V_{t s}^{m}}=\frac{\pi \cdot h^{m} \cdot \rho_{p} \cdot V_{t \max }^{2} \cdot D_{i}^{2}}{9 \cdot \mu \cdot Q} \\
V_{\text {tmax }}=V_{0 \cdot}\left[\frac{\left(\frac{D_{e}}{2}\right) \cdot\left(D_{c}-b\right) \cdot \pi}{2 a b \alpha+h^{m} \cdot\left(D_{c}-b\right) \cdot \pi \cdot \lambda}\right] \\
D_{e} \leq B, \quad h_{m}=H-s \\
D_{e} \geq B \quad h_{m}=\frac{(H-h) \cdot\left(D_{c}-D_{e}\right)}{\left(D_{c}-B\right)}+(h-s) \\
V_{o}=\frac{4 Q}{\pi \cdot D_{e}^{2}} \\
\lambda=0,02\end{array}$ \\
\hline $\begin{array}{l}\text { Leith ve Licht } \\
\text { Model(LEITH \& D., 1972) } \\
\text { [14] }\end{array}$ & $\eta_{i}=1-\exp \left\{-2 \cdot\left[\frac{G \cdot \tau_{i} \cdot Q \cdot(n+1)}{D_{c}^{3}}\right]^{1 /(2 n+2)}\right\}$ & $G=\frac{D_{c}}{a^{2} \cdot b^{2}}\left\{2 \cdot\left[\pi \cdot\left(s-\frac{a}{2}\right) \cdot\left(D_{c}^{2}-D_{e}^{2}\right)\right]+4 \cdot V_{n l, H}\right\}$ \\
\hline $\begin{array}{l}\text { lozia ve Leith Modeli } \\
{[7,15]}\end{array}$ & $D_{50}=\left(\frac{9, \mu . Q}{\pi \cdot \rho_{p} \cdot Z_{c} \cdot V_{\text {tmax }}^{2}}\right)^{0,5} \quad, \quad \eta_{i}=\frac{1}{\left[1+\left(D_{50} / D_{i}\right)^{\beta}\right]}$ & $\begin{array}{l}d_{c}=D_{c} \cdot 0,47 \cdot\left(\frac{a \cdot b}{D_{c}^{2}}\right)^{-0,25} \cdot\left(\frac{D_{e}}{D_{c}}\right)^{1,4} \\
d_{c}>B, \quad Z_{c}=(H-s)-\left[\frac{H-s}{\left(\frac{D_{c}}{B}\right)-1}\right] \cdot\left[\left(\frac{d_{c}}{B}\right)-1\right] \\
d_{c}<B, \quad Z_{c}=H-s \\
V_{t \max }=6,1 \cdot V_{i} \cdot\left(\frac{a b}{D_{c}^{2}}\right)^{0,61} \cdot\left(\frac{D_{e}}{D_{c}}\right)^{-0,74} \cdot\left(\frac{H}{D_{c}}\right)^{-0,33}\end{array}$ \\
\hline Lapple Modeli [16] & $D_{50}=\left[\frac{9 \cdot \mu \cdot b}{2 \cdot \pi \cdot N_{e} \cdot V_{i} \cdot\left(\rho_{p}-\rho_{g}\right)}\right]^{1 / 2}$ & $N_{e}=\frac{1}{a} \cdot\left[h+\frac{H-h}{2}\right]$ \\
\hline
\end{tabular}




\begin{tabular}{|c|c|c|}
\hline $\begin{array}{l}\text { Muschelknautz Modeli } \\
{[17,18,19,11]}\end{array}$ & $D_{50}=\sqrt{\frac{18 \cdot \mu \cdot(0,9 Q)}{2 \cdot \pi \cdot\left(\rho_{p}-\rho_{g}\right) \cdot V_{\theta c s}^{2}(H-S)}}$ & $V_{\theta c s}=V_{\theta w} \cdot \frac{\left(\frac{R}{R_{x}}\right)}{\left[1+\frac{f \cdot A_{R} \cdot V_{\theta w} \cdot \sqrt{R / R_{x}}}{2 \cdot Q}\right]}$ \\
\hline $\begin{array}{l}\text { The Avci and Karagoz } \\
\text { Model }[20,21]\end{array}$ & $D_{50}=0,4 \cdot \sqrt{\frac{\mu}{\left(\rho_{p}-\rho\right)} \cdot \frac{\sqrt{D_{30}} \cdot a_{h} \cdot D_{10} \cdot D_{d} \cdot a_{d} \cdot D_{s} \cdot D_{c}}{V_{0} \cdot L}} \cdot\left(\frac{10 \cdot a_{h}}{D_{30}}\right)^{c s}$ & $\begin{array}{l}c s=0,75 \cdot a_{d} \cdot \frac{D_{s}}{D_{10}} \cdot \frac{H / D_{c}}{a_{h}-0,1 \cdot D_{30}} \cdot f_{0} \\
f_{0}=f_{t}+\left(\frac{64}{R e}-f_{t}\right) \cdot e^{-\left(\frac{R e}{2560}\right)^{8}} \\
f_{t}=\frac{6,4}{[\ln (1 / R e)]^{2,4}} \\
R e=\frac{a_{h} \cdot D_{10} \cdot V_{g} \cdot D_{c}}{v} \quad a_{h}=\sqrt{a \cdot b} / D_{c} \\
D_{10}=\left[\frac{D_{c} \cdot h}{H}+\left(\frac{H-h}{H}\right) \cdot\left(\frac{D_{c}+B}{2}\right)\right] / D_{c} \\
D_{s}=D_{10}+\left(2 \cdot D_{e} \cdot s+D_{e}^{2}+B^{2}\right) /\left(H \cdot D_{c}\right) \\
a_{d}=0,5+\frac{5 a b}{\left(D_{c}-D_{e}\right) \cdot\left(D_{10} \cdot D_{c}+a+b+s\right)} \\
D_{30}=\left[\left(2 \cdot D_{e}+B\right) / 3\right] / D_{c}\end{array}$ \\
\hline $\begin{array}{l}\text { Moore ve McFarland } \\
\text { Modeli [9] }\end{array}$ & $D_{50}=\sqrt{\frac{25200 \cdot 18 \cdot \mu \cdot D}{R e^{2,72-0,119 \cdot \ln R} \cdot \rho_{p} \cdot V_{i}}}$ & $R e=\frac{\rho_{g} \cdot D \cdot V_{i}}{\mu}$ \\
\hline Li ve Wang Modeli [22] & $D_{50}=\left(\frac{0,693 \cdot D_{r} \cdot r_{w}^{n} \cdot 18^{2} \cdot \mu^{2} \cdot b \cdot\left(r_{w}^{1-n}-r_{n}^{1-n}\right) \cdot r_{w}}{(1-\alpha) \cdot(1-n) \cdot\left(\rho_{p}-\rho_{g}\right)^{2} \cdot Q \cdot u^{2} \cdot \theta_{1}}\right)^{0,25}$ & $\begin{array}{c}D_{r}=0,052 \cdot R \cdot u \cdot \sqrt{f / 8} ; f=0,02 \\
R=\left(D-D_{e}\right) / 2 ; r_{w}=D / 2 ; r_{n}=D_{e} / 2 \\
n=1-\left[\left(1-0,67 \cdot D^{0,14}\right) \cdot(T / 283)^{0,3}\right] \\
\theta_{1}=2 \pi \cdot(s+L) / a \\
u(r)=\frac{(1-n) \cdot Q}{b \cdot\left(r_{w}^{1-n}-r_{n}^{1-n}\right) \cdot r^{n}}\end{array}$ \\
\hline Sproull Modeli [23] & $D_{50}=\sqrt{\frac{0,693 \cdot 18 \cdot \mu_{g} \cdot D \cdot Q \cdot g}{\rho_{p} \cdot V_{t}^{2} \cdot A_{c}}}$ & $\begin{array}{c}A_{c}=\pi \cdot D \cdot h+\frac{\pi}{2} \cdot(D+B) \cdot\left[(H-h)^{2}+\left(\frac{D-B}{2}\right)^{2}\right]^{0,5} \\
V_{t}: \text { Teğetsel Gaz Hızı }\end{array}$ \\
\hline Clift ve ark. Modeli [24] & $D_{50}=\sqrt{\frac{0,693 \cdot 18 \cdot \mu \cdot D}{c^{\prime} \cdot \rho_{p} \cdot V_{i}}}$ & $\begin{array}{c}c^{\prime}=2 \cdot \frac{\pi \cdot D^{2}}{a \cdot b} \cdot\left[\left(1-\left(\frac{D_{e}}{D}\right)^{2}\right) \cdot\left(\frac{s}{D}\right)+\frac{1}{3} \cdot\left(\frac{s+l-h}{D}\right) \cdot\left(1+\frac{d}{D}+\left(\frac{d}{D}\right)^{2}\right)+\frac{h}{D}\right. \\
\left.-\left(\frac{D_{e}}{D}\right)^{2} \cdot \frac{l}{D}-\frac{s}{D}\right] \\
\frac{l}{D}=2,3 \cdot \frac{d_{e}}{D} \cdot\left(\frac{D^{2}}{a \cdot b}\right)^{1 / 3} ; \frac{d}{D}=\frac{D-(D-B) \cdot\left[\frac{s+l-h}{H-h}\right]}{D}\end{array}$ \\
\hline
\end{tabular}

\section{Sonuçlar}

Siklon ayırıcılarda diğer parametreler sabit tutulduğunda sadece giriş hızı veya debi değiştiğinde parçacık kritik çapının veya verimin değişimi ele alınmıştır. Dikkate alınan matematik modeller literatürde yaygın kullanımı olan modellerdir. Bu modellerde farklı geometri ve büyüklüklerde siklonlarla yapılan ve hızın etkisini dikkate alan deneysel çalışmalar esas alınarak bu siklonlar da matematik modellerin tahmini kritik çap değerleri ile deneysel kritik çap değerleri karşılaştırılmıştır. Karşılaştırmada mutlak değerlerden ziyade hızdaki değişim oranı ile kritik çaplardaki değişim oranları arasındaki ilişki karşılaştırma açısından esas alınmış ancak mutlak değerlerde verilmiştir. Siklon ayırıcılarda giriş hızının artması ile siklon veriminin arttığı yani 
kritik çap değerinin azaldığ 1 genel olarak bilinmektedir. Ancak bu durum akış rejiminde değişikliğe bağlı olarak değişebilmektedir. Yine hızın etki mertebeleri de farklı olabilmektedir. Hesaplama için kullanılan modellerde genel olarak kritik çap, giriş hızının karekökü ile ters orantılı olarak değişmektedir. Barth, Leith ve Licht, Iozia ve Leith, Lapple, Li ve Wang, Sproull ve Clift ve ark. Modelleri bu kapsamda sayılabilir. Bu modellerde sürtünme faktörü sabit kabul edildiğinden giriş hızının değişimi ile kritik çap üzerinde ilave bir etki olmamaktadır. Buna karşılık Avcı ve Karagöz, Muschelknautz ve Moore ve McFarland modellerinde ilave etki olarak sürtünme faktörü hıza bağlı olarak hesaplanır ve bu değişimden dolayı ilave bir etki oluşur. Giriş hızının değişimi ile Reynolds sayısı dolayısıyla sürtünme faktörü değişmektedir. Bunu dikkate alan modellerde kritik çapta da ilave değişim meydana gelmektedir. Siklon ayırıcılardaki akışta Reynolds sayısının tanımı ve sürtünme kayıp katsayısıyla ilişkisinin elde edilmesi de önemli bir problem olarak görünmektedir.

$\mathrm{Bu}$ çalışmanın amacı açısından matematik modeller kullanılarak hesaplanan kritik çap değerlerinin ve deneysel olarak bulunan kritik çap değerlerinin oransal olarak giriş hızının değişim oranına göre değerleri hesaplanarak sonuçlar şekil 3' te verilmiştir. Bu grafikte farklı siklonlarda farklı hızlar için elde edilen 126 deneysel değer için hesaplanan değerler verilmiştir. Deneysel ve matematik model ile oluşturulan sonuçların hız değişimi ile uyumlu olduğu noktaların yeri doğru ile gösterilmiştir. Bu sonuçlara göre genel olarak kritik çap hız oranının karekökünden daha hızlı değişmektedir. Düşük hız oranlarında kritik çaptaki değişimde küçük olduğundan hesapla deneysel veriler yakın sonuçlar vermekte ancak oranlar büyüdügünde sapma artmaktadır. $\mathrm{Bu}$ açıdan ilave etkiyi dikkate almayan modellerde hız oranındaki değişimin karekökü ile kritik çap değişmektedir. İlave etkiyi dikkate alan modellerde ise uyum daha iyi görünmektedir. Bu modellerde de özellikle Zhu \& Lee, (1999)'den alınan deneysel verilerde 25 $\mathrm{m} / \mathrm{s}$ civarında hızlarda deneysel kritik çapta ani düşüşler olmaktadır. Bu ani değişim modeller tarafından tahmin edilememektedir. Literatürde de bu ani değişimi doğrulayacak yeterli veri bulunmamaktadır. Bu dikkat çekici bir durumdur. Bunun dışındaki değerlerde genelde uyum iyidir.

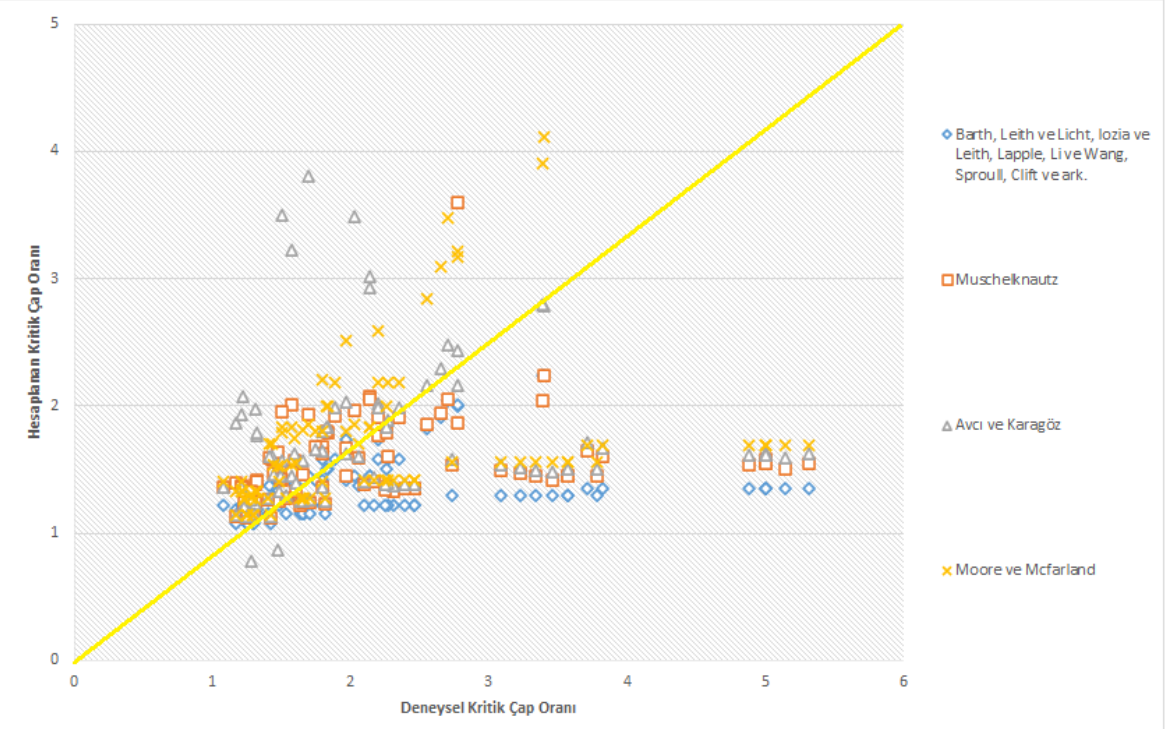

Şekil 3. Giriş hızı değişimi ile hesaplanan kritik çap oranı ile deneysel kritik çap oranı kıyaslanması 
Diğer bir değerlendirme ölçütü olarak giriş Re sayısı kullanılmıştır. Giriş Re sayısı ile model oranının deneysel orandan sapma miktarı hesaplanmış ve sonuçlar şekil 4'de verilmiştir. Bu sonuçlara göre Re sayıları 10000 üzerinde olan siklonlarda model tahminleri deneysel verilerle daha iyi uyum sağlarken düşük Re sayılarında sapma artmaktadır. Bu durum akış rejiminin değişim gösterdiği ve laminere kaydığı bölgelerde oluştuğu söylenebilir. Bu bölgede Re sayısı ile sürtünme kayıp katsayısı arasındaki ilişkinin daha uyumlu olması ve buna göre tanımlanması gerekir.

Matematik modeller için diğer bir çalışma ise mutlak değer olarak sonuçların karşılaştırılmasıdır. Matematik modellerle elde edilen kritik çap değerleri ve deneysel kritik çap değerleri karşılaştırılmış deneysel verilere göre mutlak hata ve mutlak kare hata değerleri Tablo 2' de ayrı ayrı verilmiştir.

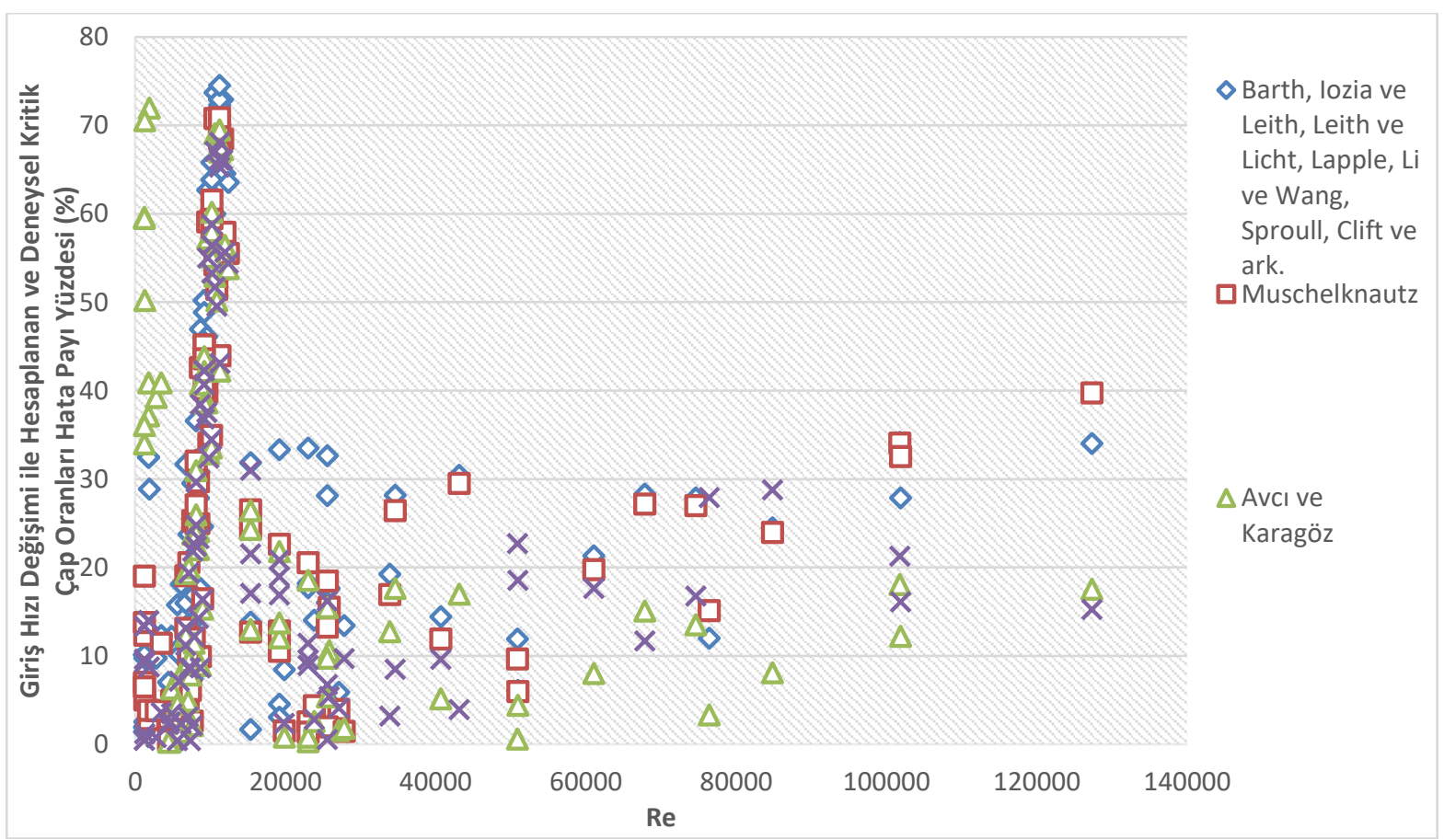

Şekil 4. Farklı Re sayılarında giriş hızı değişimi ile modellerin hata payı yüzdeleri

Mutlak hata değerleri incelendiğinde giriş hızı için en iyi sonuçları veren ilk üç model sırasıyla Avcı ve Karagöz, Iozia ve Leith ve Lapple modelleridir. Mutlak kare hata değerlerine bakıldığında ise en iyi sonuçları veren modeller Barth, Lapple ve Iozia ve Leith modelleridir. Bu tür bir karşılaştırma diğer parametrelerin etkisini de birlikte ele aldığından doğrudan hızın etkisini anlamaya imkan vermez. Sonuçlar şekil 5' te verilmiştir. Buradan anlaşılacağı gibi bazı modeller deneysel verilere daha yakın ancak altında veya üstünde iken bazılarında daha simetrik dağılım göstermektedir. Bir kısmı ise daha fazla sapma yapmaktadır. 
Table 2. Farklı matematiksel modeller için hesaplanan değerler ile deneysel ölçülen değerlerin hata değerleri

\begin{tabular}{ccc}
\hline Model & e & $\mathbf{E}^{\wedge} \mathbf{2}$ \\
\hline Barth & $9,67564 \mathrm{E}-07$ & $1,61747 \mathrm{E}-12$ \\
Leith ve Licht & $1,5233 \mathrm{E}-06$ & $4,93225 \mathrm{E}-12$ \\
Iozia ve Leith & $9,23311 \mathrm{E}-07$ & $2,17868 \mathrm{E}-12$ \\
Lapple & $9,37386 \mathrm{E}-07$ & $1,75462 \mathrm{E}-12$ \\
Muschelknautz & $1,05744 \mathrm{E}-06$ & $3,08403 \mathrm{E}-12$ \\
Avc1 ve Karagöz & $7,67137 \mathrm{E}-07$ & $2,28107 \mathrm{E}-12$ \\
Moore ve McFarland & $3,4859 \mathrm{E}-06$ & $2,0186 \mathrm{E}-11$ \\
Li ve Wang & $1,08556 \mathrm{E}-06$ & $3,34982 \mathrm{E}-12$ \\
Sproull & $8,57991 \mathrm{E}-06$ & $1,16423 \mathrm{E}-10$ \\
Clift ve ark. & $1,15445 \mathrm{E}-06$ & $2,94182 \mathrm{E}-12$ \\
\hline
\end{tabular}

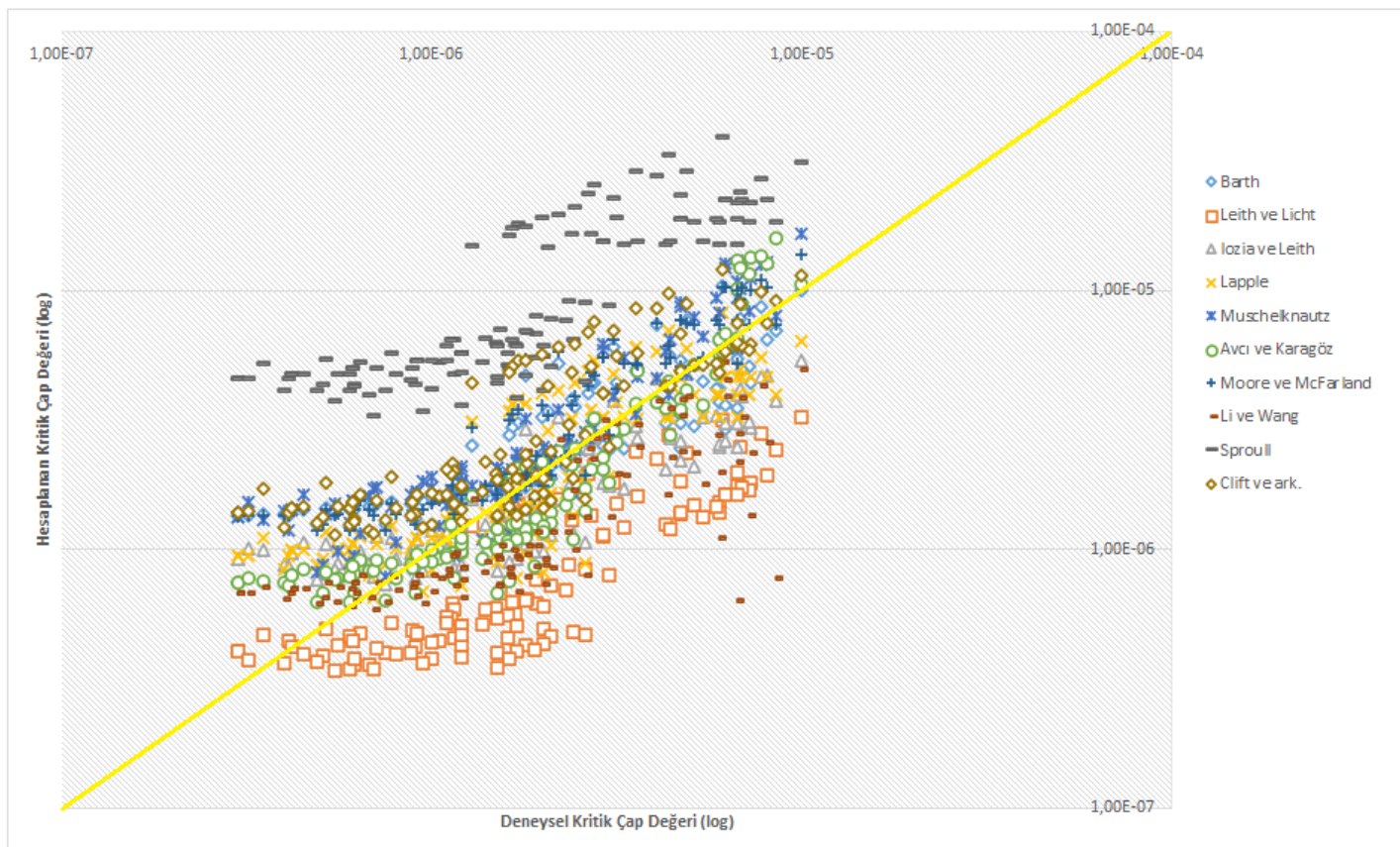

Şekil 5. Hesaplanan değerler ile deneysel kritik çap değerleri

\section{Tartışma}

Matematik modeller için yapılan hesaplama çalışmalarına ait sonuçlar dikkate alındığında matematik modellerin kullanımı ile ilgili olarak dikkate alınabilecek hususlar birkaç madde olarak siralanabilir:

- Giriş hızının verime ve kritik çapa etkisi hızın karekökünden daha hızlı değişim gösterir. Bu nedenle ilave etkiyi dikkate alan matematik modellerin tahmin kabiliyeti daha yüksektir.

- İlave etkide önemli parametre sürtünme kayıp katsayısı olup bunun Re sayısı ile ilişkisi önemlidir.

- Yüksek Re sayılarında modellerin tahmin kabiliyeti daha yüksek olup laminer bölgeye kaydıkça hata oranları artmaktadır. Küçük siklonlarda ve düşük hızlarda hata daha yüksek olabilir. 
- Geçiş ve laminer bölge için Re sayısı ile sürtünme katsayısı arasındaki ilişki ve bunun modele katkısı üzerinde çalışmalar yapmak gerekmektedir.

- Akış rejim bölgelerinin tanımı da çalışılması gereken önemli bir konudur.

- Deneysel çalışmalardaki hata payları dikkate alınmalıdır.

\section{Kaynaklar}

[1] Xiang R, Park SH, Lee KW. Effects of cone dimension on cyclone performance. Journal of Aerosol Science 2001; 32(4), 549-561. https://doi.org/10.1016/S0021-8502(00)00094-X

[2] Ji Z, Xiong Z, Wu X, Chen H, Wu H. Experimental investigations on a cyclone separator performance at an extremely low particle concentration. Powder Technology 2009; 191(3), 254-259. https://doi.org/10.1016/j.powtec.2008.10.015

[3] Kim JC, Lee KW. Experimental study of particle collection by small cyclones. Aerosol Science and Technology 1990; 12(4), 1003-1015. https://doi.org/10.1080/02786829008959410

[4] Beeckmans JM, Kim CJ. Analysis of the efficiency of reverse flow cyclones. The Canadian Journal of Chemical Engineering 1977; 55(6), 640-643.

[5] Dirgo J, Leith D. Cyclone collection efficiency: comparison of experimental results with theoretical predictions. Aerosol Science and Technology 1985; 4(4), 401-415. https://doi.org/10.1080/02786828508959066

[6] Huang AN, Maeda N, Shibata D, Fukasawa T, Yoshida H, Kuo HP, Fukui K. Influence of a laminarizer at the inlet on the classification performance of a cyclone separator. Separation and Purification Technology 2017; 174, 408-416.

https://doi.org/10.1016/j.seppur.2016.09.053

[7] Iozia DL, Leith D. The Logistic Function and Cyclone Fractional Efficiency The Logistic Function and Cyclone Fractional Efficiency. Aerosol Science and Technology 1990; 6826(12), 598-606. https://doi.org/10.1080/02786829008959373

[8] Kim GN, Choi WK, Jung CH. The development and performance evaluation of a cyclone train for the removal of contaminated hot particulate in a hot cell. Separation and $\begin{array}{llll}\text { Purification } & \text { Technology 2007; 313-320. }\end{array}$ https://doi.org/10.1016/j.seppur.2006.12.019

[9] Moore ME, McFarland AR. Design of Stairmand-Type Sampling Cyclones*. American Industrial Hygiene Association Journal 1990; 51(3), 151-159. https://doi.org/10.1080/15298669091369475

[10] Zhu Y, Lee KW. Experimental study on small cyclones operating at high flowrates. Journal of Aerosol Science 1999; 30(10), pp. 1303-1315. https://doi.org/10.1016/S0021$\underline{8502(99) 00024-5}$

[11] Hoffmann AC, Stein LE. Gas cyclones and swirl tubes: Principles, design and operation. $2^{\text {nd }}$ ed. 2008. https://doi.org/10.1007/978-3-540-74696-6

[12] Leith D, Jones DL. Cyclones. In: Handbook of Powder Science \& Technology; 1997 ss. 727-752. https://doi.org/10.1007/978-1-4615-6373-0_15

[13] Barth W. Berechnung und Auslegung von Zyklonabscheidern auf Grund neuer Untersuchungen. Brennst.-Warme-Kraft, 1956; 8, 1-9.

[14] Leith D, Licht W. The collection efficiency of cyclone type particle collectors-a new theoretical approach. Air Pollution and Its Control, AlChE Symp. Ser., 1972; 68(126). 
[15] Iozia DL, Leith D. Effect of Cyclone Dimensions on Gas Flow Pattern and Collection Efficiency. Aerosol Science and Technology, 1989; 10, 491-500. https://doi.org/10.1080/02786828908959289

[16] Lapple CE. Processes use many collection types. Chem. Eng., 1951; 58(5), 144-151.

[17] Muschelknautz, E. Die Berechnung von Zyklonabscheidern für Gase. Chemie Ingenieur Technik, 1972; 44(1-2), 63-71. https://doi.org/10.1002/cite.330440112

[18] Muschelknautz E, Trefz M. Design and calculation of higher and design and calculation of higher and highest loaded gas cyclones. in 'Proceedings of Second World Congress on Particle Technology' Kyoto, Japan, pages 52-71, October 1990.

[19] Muschelknautz E, Trefz M. VDI-W"armeatlas. Druckverlust und Abscheidegrad in Zyklonen, 6 Auflage:Lj1 - Lj9, 1991.

[20] Avci A, Karagoz, I. Effects of flow and geometrical parameters on the collection efficiency in cyclone separators. Journal of Aerosol Science, 2003; 34(7), 937-955. https://doi.org/10.1016/S0021-8502(03)00054-5

[21] Avci A, Karagoz I. A new explicit friction factor formula for laminar, transition and turbulent flows in smooth and rough pipes. European Journal of Mechanics, B/Fluids, 2019; 78, 182-187. https://doi.org/10.1016/j.euromechflu.2019.07.007

[22] Enliang L, Yingmin W. A new collection theory of cyclone separators. AIChE Journal, 1989; 35(4), 666-669. https://doi.org/10.1002/AIC.690350419

[23] Sproull WT. Air Pollution and Its Control. Exposition Press: New York, USA; 1970.

[24] Clift R, Ghadiri M, Hoffman AC. A critique of two models for cyclone performance. AIChE Journal, 1991; 37(2), 285-289. https://doi.org/10.1002/aic.690370217 